\title{
Influence of Carbide Formation on Tensile and Fatigue Properties of Carburized Steels
}

\author{
Eunji Yu, Heejong Jung ${ }^{1}$, Kun-Su Kim² ${ }^{2}$ Eui-Jun Kim ${ }^{3}$, Jongryoul Kim ${ }^{4, *}$ \\ Sheet Products Design Team, Technical Research Center, Hyundai Steel Company, Dangjin 343-711, Korea \\ ${ }^{1}$ Special Steel Development Team, Technical Research Center, Hyundai Steel Company, Dangjin 343-711, Korea \\ ${ }^{2}$ Department of Materials Science and Engineering, Seoul National University, Seoul 151-744, Korea \\ ${ }^{3}$ Materials Research Team, Hyundai Kia Motors, Hwaseong 445-706, Korea \\ ${ }^{4}$ Department of Metallurgy and Material Science, Hanyang University, Ansan 425-170, Korea
}

*Correspondence to:

Kim J,

Tel: +82-31-400-4279

Fax: +82-31-436-8146

E-mail: jina@hanyang.ac.kr

Received June 11, 2013

Revised June 14, 2013

Accepted June 14, 2013
The influence of carbide formation on mechanical properties has been investigated in carburized steels. Through controlled diffusion and precipitation processes, the morphologies of carbides could be changed and then fine, networked, and spherical shapes at carburized layers were obtained. These morphological changes affected tensile and bending fatigue properties of the steel. The fine and the spherical carbides acted as resistance sites against crack propagation, which improved the mechanical properties. However, the networked carbides deteriorated the properties because the cracks propagated along the boundaries of them. These results indicate that the morphological control of carbides is one of important keys to improve the mechanical properties.

Key Words: Carburized steel, Carburization, Carbides, Tensile properties, Bending fatigue property

\section{INTRODUCTION}

In recent years, there has been a strong demand for extending the life time of machine components and structures due to economic and environmental factors. Many machine parts used for heavy duty application, such as shafts, gears, and cams often demand a very hard surface that can resist wear as well as a soft, but tough core that can withstand the impact stresses. An established method for the production of a combination hard surface/soft but tough core is case hardening of steels through carburizing and quenching (Farfána et al., 2004; Liu \& Chen, 2004; Tokaji et al., 2004).

The conventional carburizing process is performed by the absorption and diffusion of carbon atoms from the carburizing atmosphere to a steel matrix, thus increasing carbon content to approximately $0.8 \mathrm{wt} \%$ at austenite temperature within a carburized layer that is hardened by quenching (An et al., 2003; Erdogan \& Tekeli, 2003; Akita \& Tokaji, 2006; Michal et al., 2006). With the additional precipitation process after the conventional carburizing process, carbides can be formed in grain boundaries with a networked type. The super carburizing process can be used to form spherical type carbides by means of repeated carburizing treatment. In this process, upon reheating the carburized steel, small carbides redissolve into the austenite matrix, while larger carbides remain as nuclei or embryos for the growth of spherical carbides in the re-carburizing stage. It was reported that the number of carbides accumulated at the surface of a specimen increased with the number of carburization-precipitation cycles (Chen \& Wang, 2000; Liu \& Chen, 2004).

Although the morphological changes of carbides and the corresponding hardness data were examined and reported, there is still a lack of a detailed relationship between carbide shapes and mechanical properties, particularly tensile and fatigue properties. Therefore, this study aims to clarify the effects of carbide shapes on mechanical properties of carburizing steels.

(a) This is an open-access article distributed under the terms of the Creative Commons Attribution Non-Commercial License (http://creativecommons.org/licenses/by-nc/3.0) which permits unrestricted noncommercial use, distribution, and reproduction in any medium, provided the original work is properly cited.

Copyrights @ 2013 by Korean Society of Microscopy 
Table 1. Chemical composition (wt\%) of the KS-SCR420 (Hyundai Kia Motors, Hwaseong, Korea)

\begin{tabular}{ccccccccc}
\hline $\mathrm{C}$ & $\mathrm{Si}$ & $\mathrm{Mn}$ & $\mathrm{P}$ & $\mathrm{Cu}$ & $\mathrm{Ni}$ & $\mathrm{Cr}$ & $\mathrm{Mo}$ & $\mathrm{Nb}$ \\
\hline 0.21 & 0.26 & 0.87 & 0.016 & 0.16 & 0.15 & 0.124 & 0.7 & 0.023 \\
\hline
\end{tabular}

Table 2. Carburizing processes of the specimens

\begin{tabular}{cc}
\hline No. & Carburizing processes \\
\hline 1 & 120 min. $\mathrm{C}\left(950^{\circ} \mathrm{C}\right)-60 \mathrm{~min} . \mathrm{D}\left(950^{\circ} \mathrm{C}\right)-30 \mathrm{~min} . \mathrm{P}\left(600^{\circ} \mathrm{C}\right)-40 \mathrm{~min} . \mathrm{H}$ \\
& $\left(800^{\circ} \mathrm{C}\right)$-oil quenching \\
2 & 150 min. $\mathrm{C}\left(950^{\circ} \mathrm{C}\right)-40$ min. $\mathrm{P}\left(600^{\circ} \mathrm{C}\right)-40 \mathrm{~min} . \mathrm{H}\left(800^{\circ} \mathrm{C}\right)$-oil \\
& quenching \\
3 & {$\left[60\right.$ min. $\mathrm{C}\left(950^{\circ} \mathrm{C}\right)-30$ min. $\mathrm{D}\left(950^{\circ} \mathrm{C}\right)-15$ min. $\left.\mathrm{P}\left(600^{\circ} \mathrm{C}\right)\right]-[30$ min. $\mathrm{C}$} \\
& $\left(95^{\circ} \mathrm{C}-15\right.$ min. $\mathrm{D}\left(950^{\circ} \mathrm{C}\right)-15$ min. $\left.\mathrm{P}\left(600^{\circ} \mathrm{C}\right)\right] \times 3$ times- 40 min. $\mathrm{H}$ \\
& $\left(800^{\circ} \mathrm{C}\right)$-oil quenching \\
\hline
\end{tabular}

C, carburization; D, diffusion; $\mathrm{P}$, precipitation; $\mathrm{H}$, holding.

\section{MATERIALS AND METHODS}

\section{Carburizing Processes}

The chemical composition of as-rolled bar steels (KS-SCR420) supplied from Hyundai Kia Motors (Hwaseong, Korea) is shown in Table 1. To fabricate carbides with different morphologies, three different carburizing procedures were used in this experiment, and the carburizing conditions are summarized in Table 2. As shown in Table 2, the process $\# 1$ conducted the diffusion process after carburizing for carbon diffusion into the matrix but the process \#2 skipped the diffusion process for the restriction of carbon diffusion. The process \#3 repeated the carburizing, diffusion and precipitation processes in order to make spherical type carbides.

\section{Mechanical Properties and Microstructure Analysis}

The hardness profiles of carburized steels were measured by a micro vickers hardness tester (Hv, 420MVD; Wolpert Wilson Instruments). A load of $2.94 \mathrm{~N}$ was applied to measure the hardness from the surface to the core, and an effective case depth $(\mathrm{ECD}, \mathrm{mm})$ was defined as the distance below the surface where the hardness was equal to $550 \mathrm{Hv}$ (Elkholy, 1983; Parrish, 1999; Liu \& Chen, 2004).

The mechanical properties of the carburized steels were analyzed by tensile and bending fatigue tests. The tensile strength was measured by a tensile tester (MTS 810; MTS). Specimens for the tensile test were prepared under ASTM A 370 and the working load was $245 \mathrm{kN}$. The fatigue test was carried out on a bending fatigue tester (Instron 8516; Instron) at room temperature, and the fatigue limit was assumed to be maximum bending stress at $10^{7}$ cycles. The standard specimen for the test is shown in Fig. 1.

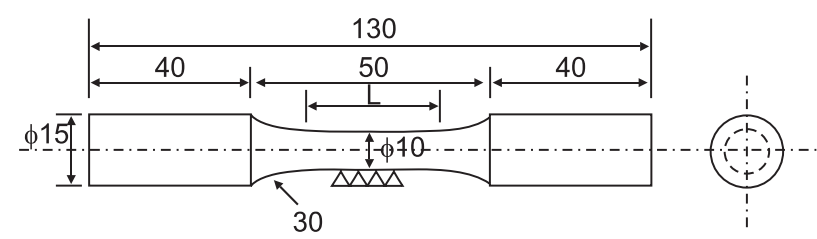

Fig. 1. Specimens drawing of the bending fatigue test specimen. Dimensions in $\mathrm{mm}$.

The formation and the shape of carbides were confirmed by an optical microscopy (OM, Olympus GX51; Olympus, Tokyo, Japan) after 2\% nital etching. A detailed microstructural analysis of the carbides was conducted by transmission electron microscopy (TEM, Jeol, JEM 2010) after the jet thinning method. The fractographies after tensile and fatigue tests were observed by a scanning electron microscopy (SEM, Tescan, MIRA-3).

\section{RESULTS AND DISCUSSION}

\section{Microstructures and Hardness Profiles of the Carburized Layer}

Fig. 2 shows the microstructures of as-rolled and carburized steels. As shown in Fig. 2A, the as-rolled bar steel had a typical microstructure that consisted of ferrite and pearlite phases, and the average grain size measured about $14 \mu \mathrm{m}$ using an image analyzer. As shown in Fig. 2B-D, the formation of three different type carbides (bright areas in the figures indicate carbides) were observed in carburized layers. In addition, any noticeable grain growth in all the samples was not observed, but the ferrite and pearlite phases changed into the martensite phase. In the process \#1, carbon atoms were expected to diffuse into the Fe matrix during the diffusion process and then the diffused atoms formed fine carbides both inside the matrix and on grain boundaries through the precipitation process, confirmed by an enlarged micrograph in Fig. 2B. The average size of the carbides decreased from 2.8 $\mu \mathrm{m}$ in the top surface region to $1.7 \mu \mathrm{m}$ in the bottom region of the carburized layer. However, the process \#2 skipped the diffusion process, which prohibited the diffusion of carbon atoms into the matrix. Thus, created carbides were formed along the grain boundaries during the precipitation process, which made networked carbides along the boundaries, as shown in Fig. 2C. Fig. 2D clearly shows that spherical carbides (from $4.5 \mu \mathrm{m}$ in the top surface region to $2.5 \mu \mathrm{m}$ in the bottom region of the carburized layer) were fabricated by the process \#3. In this process, carbides initially formed both grains and grain boundaries due to a short diffusion time and then dissolved into the Fe matrix during the repeated diffusion process, re-formed again during the repeated precipitation process, and finally formed the spherical type carbides with a uniform distribution. The microstructure of 

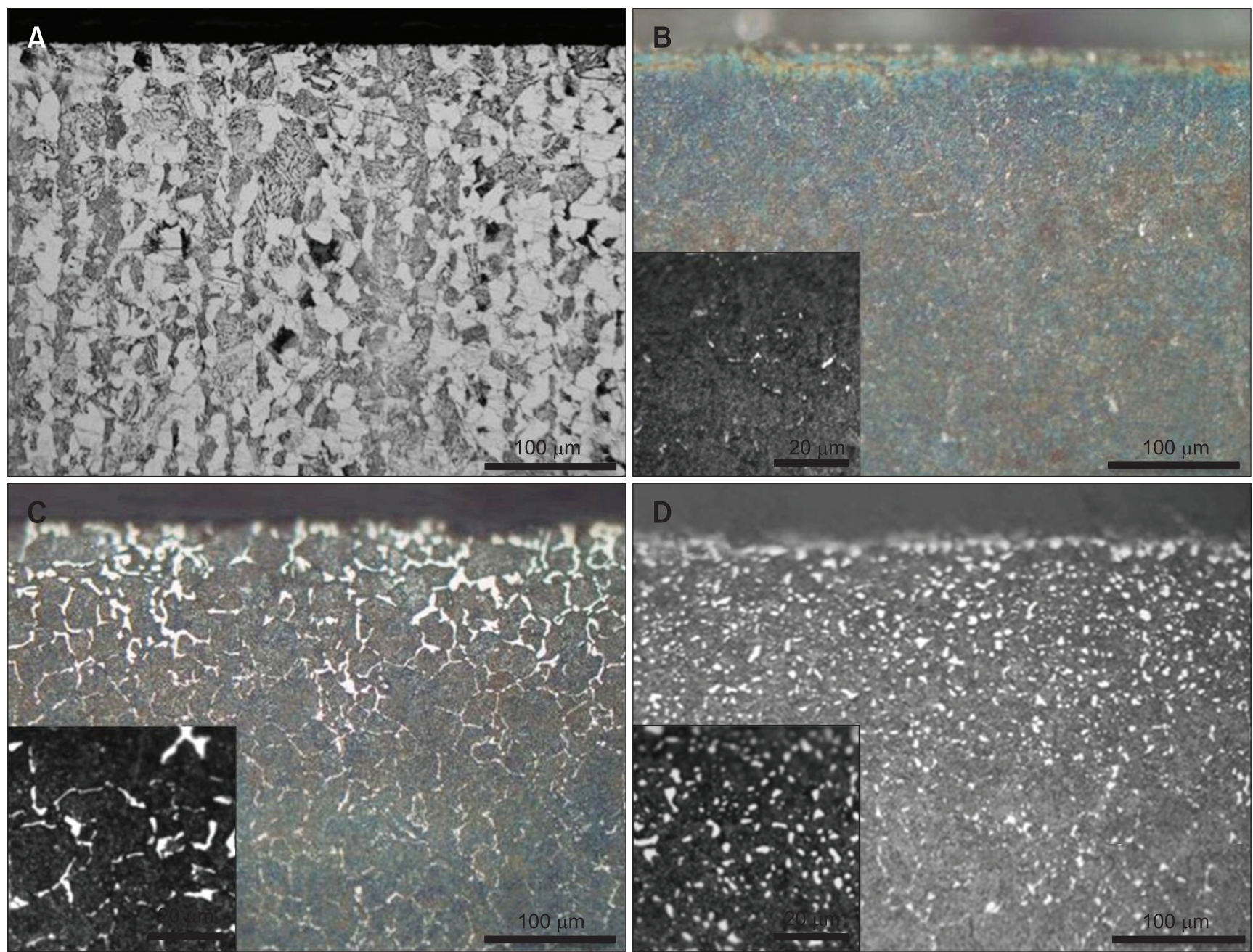

Fig. 2. Microstructures of as-rolled (A) and carburized steels; fine carbides (B), networked carbides (C) and spherical carbides (D).
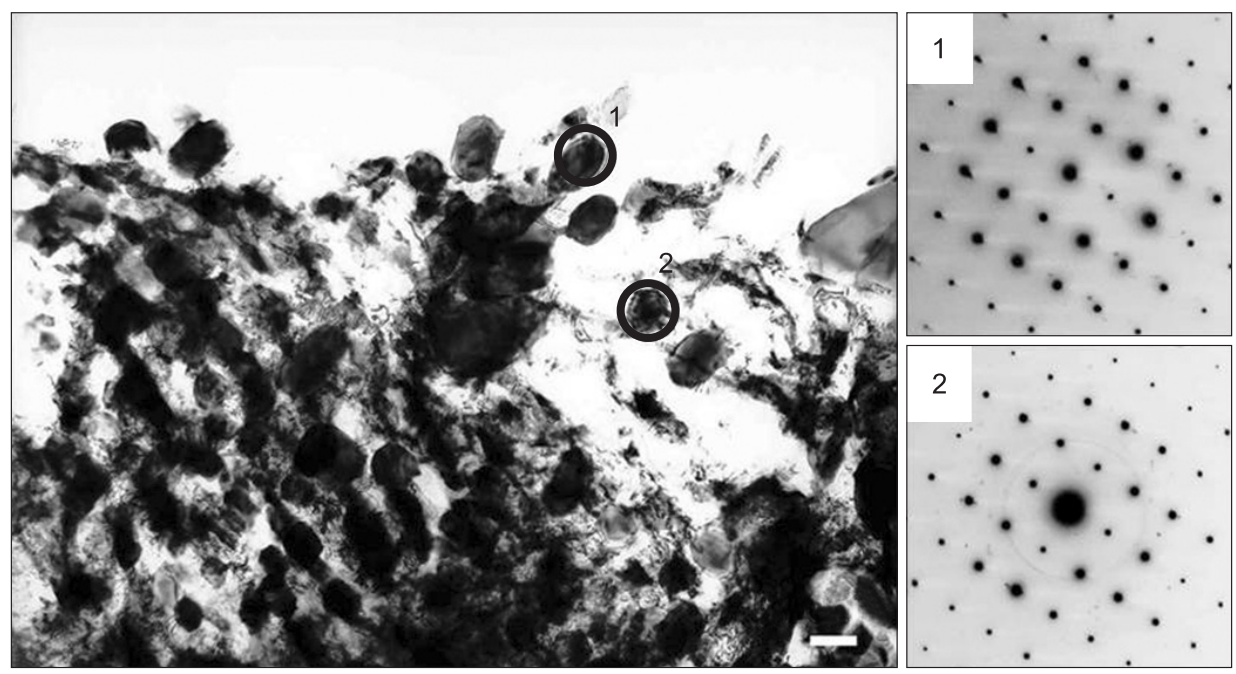

Fig. 3. TEM micrograph and SAD patterns of the no. 3 process. 

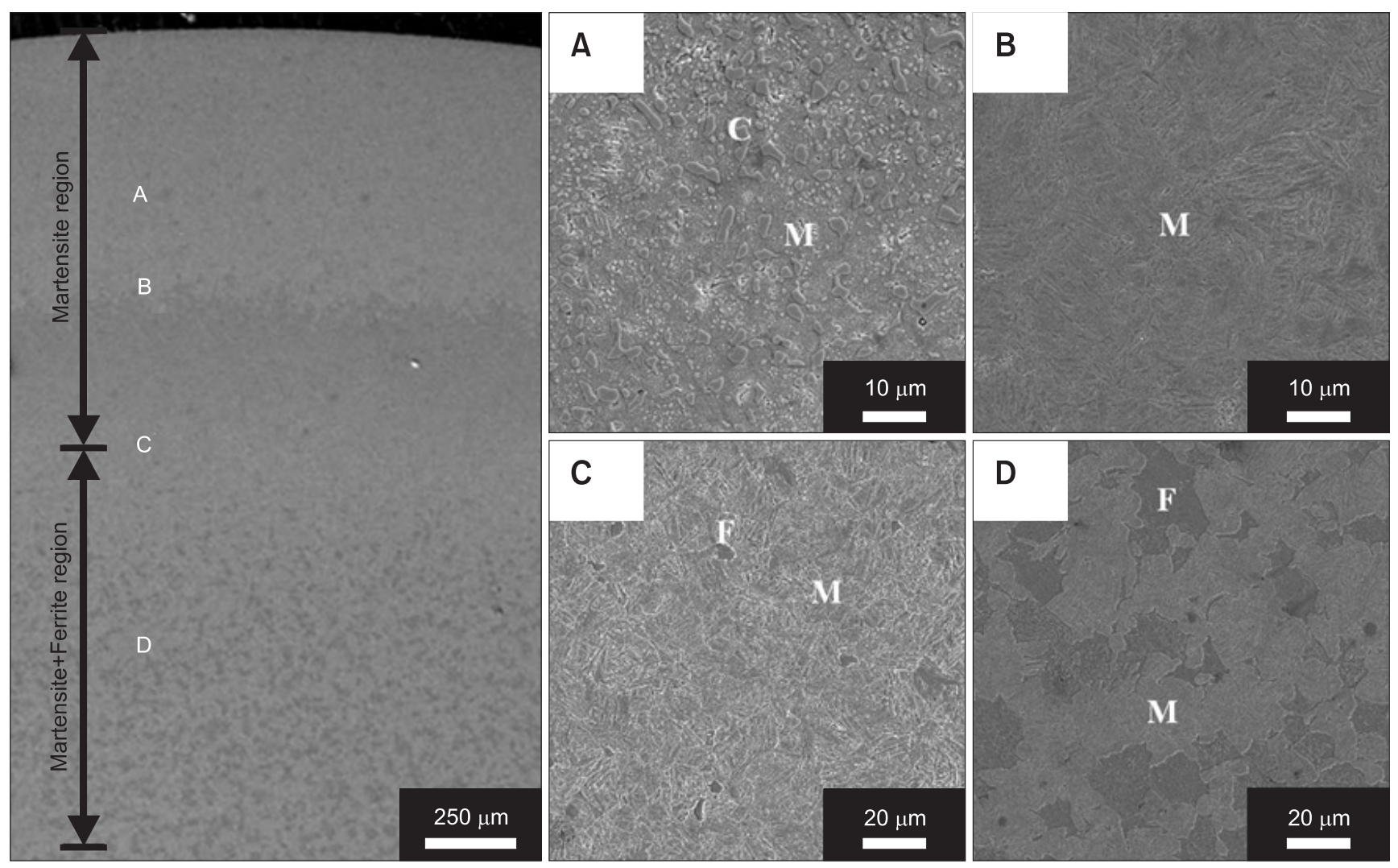

Fig. 4. Microstructures by depth of the no. 3 process. C, carbide; M, martensite; F, ferrite.

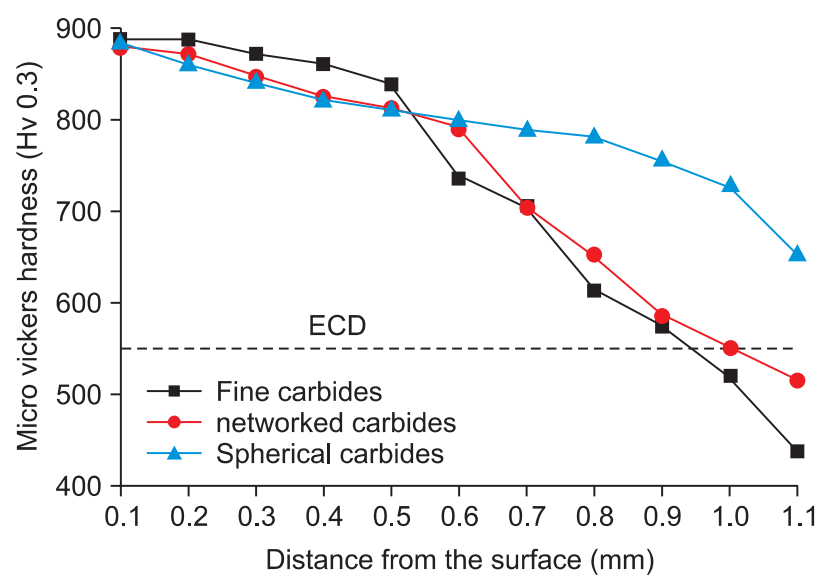

Fig. 5. The hardness profiles and effective case depth (ECD) of the carburized layer.

the carbides was investigated by the selected area diffraction patterns. As shown in Fig. 3, carbides were identified as a $\mathrm{Fe}_{3} \mathrm{C}$ structure despite the carburizing conditions. And the microstructures by depth in the carburized layer are shown in Fig. 4. As shown in the figure, the martensite obtained at about $0.8 \mathrm{~mm}$ from the surface with or without carbide, and the martensite and ferrite existed below that. These results

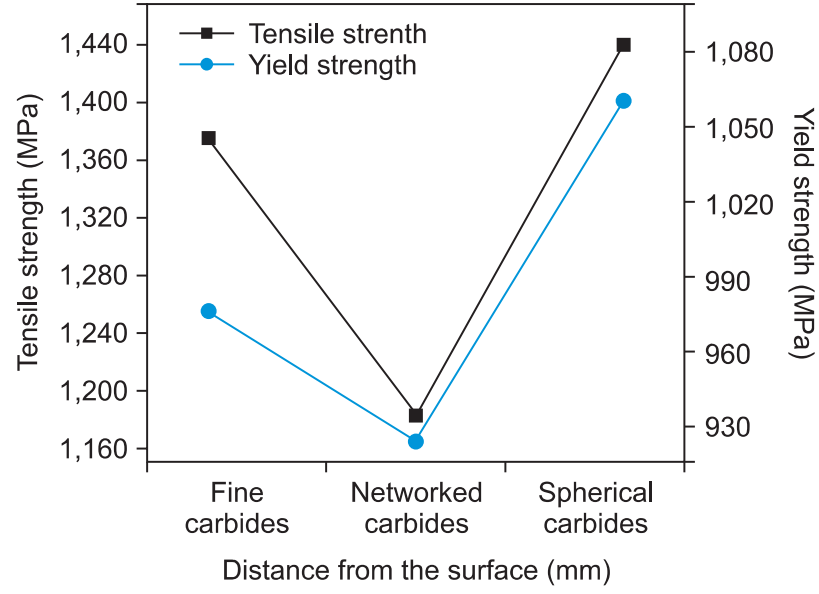

Fig. 6. Tensile properties as a function of carbides.

proved that the $\mathrm{Fe}_{3} \mathrm{C}$ carbides with different morphologies were successfully fabricated.

The depth profiles of the hardness as a function of the carbides types are shown in Fig. 5. The surface hardness of all samples was almost the same at $880 \mathrm{Hv}$. As the depth increased, the hardness decreased, which might be strongly related to the carbon contents. As shown in the figure, the 
hardness in samples with fine and networked carbides dropped abruptly at a certain distance, and a sample with spherical carbides had the longest ECD of the carburized layers. This abrupt change of the hardness and the difference of ECD correlated with the density changes of the carbides, as shown in Fig. 2. In particular, the repeated processes enhanced carbon diffusion into the matrix rather than the formation of carbides in the sample with the spherical carbides. This carbon diffusion could also explain the initial lower hardness as compared with the sample with the fine carbides.

\section{Tensile Properties}

Fig. 6 shows the tensile and yield strength changes with carbides types. As shown in the figure, the minimum and
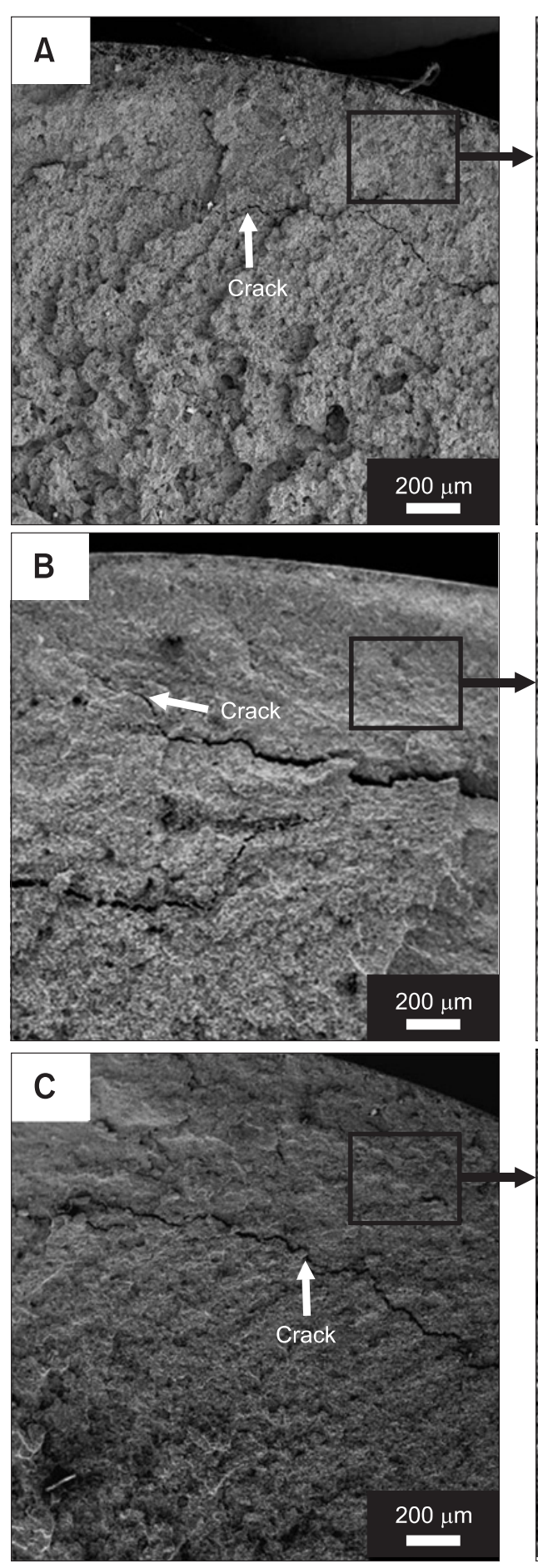
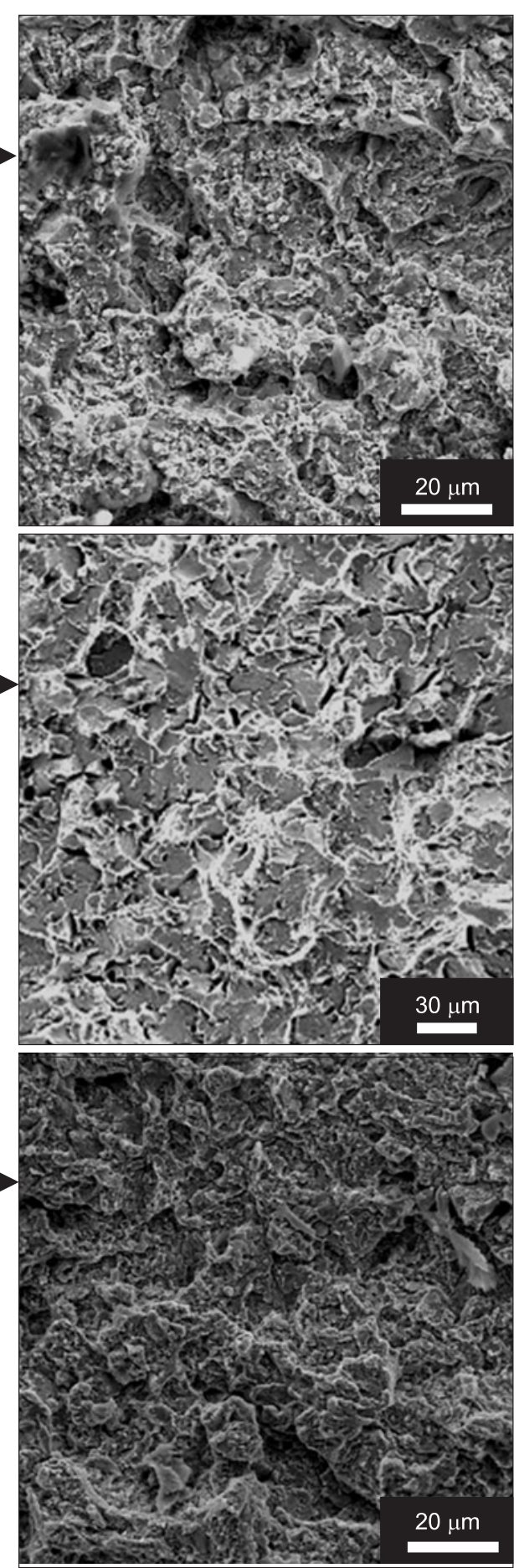

Fig. 7. Fractographies after tensile tests as a function of carbides: fine carbides (A), networked carbides (B) and spherical carbides (C). 
maximum values of yield and tensile strength were obtained in samples with networked carbides and spherical carbides,

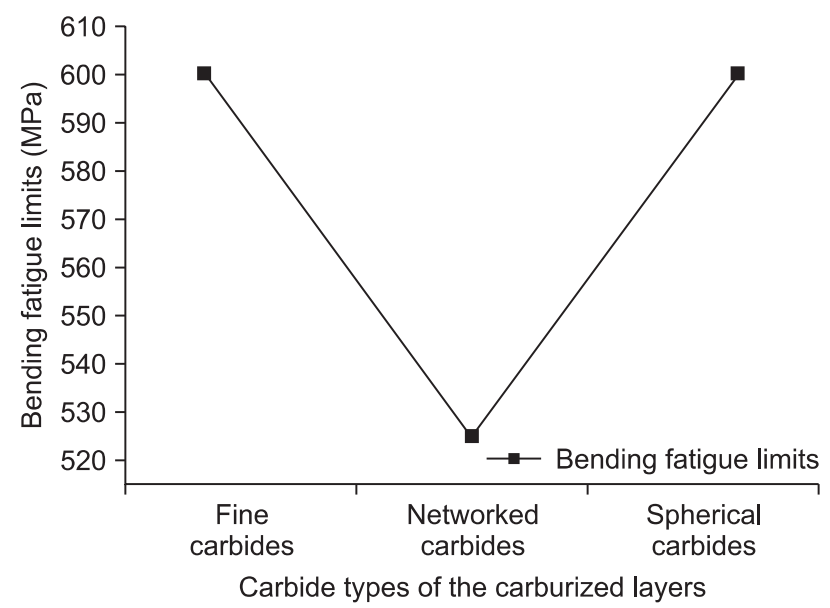

Fig. 8. Bending fatigue limits as a function of carbides. respectively. The elongation values measured 1.76\%, 1.34\% and $1.54 \%$ in samples with fine, networked and spherical carbides, respectively. In order to understand the mechanical behaviors, the fractographies of the samples after tensile tests were investigated and are shown in Fig. 7. As shown in the figures, cracks were propagated along the circumferential direction in all the samples. However, some cracks in the sample with the networked carbides were observed to progress toward the surface. The cracks initiated in the intermediate layers which consisted of different phases (martensite and ferrite), in all conditions. In the vicinity of these layers, the hardness also dropped abruptly, as shown in Fig. 5. Therefore, the cracks were easily formed and propagated along the interface of the phases by the applied force.

More detailed fractographies of the sub-surface showed that minor cracks in a sample with networked carbides progressed along grain boundaries. However, samples with fine and spherical carbides showed dimples indicating that carbides resisted the propagation of cracks. These results proved that
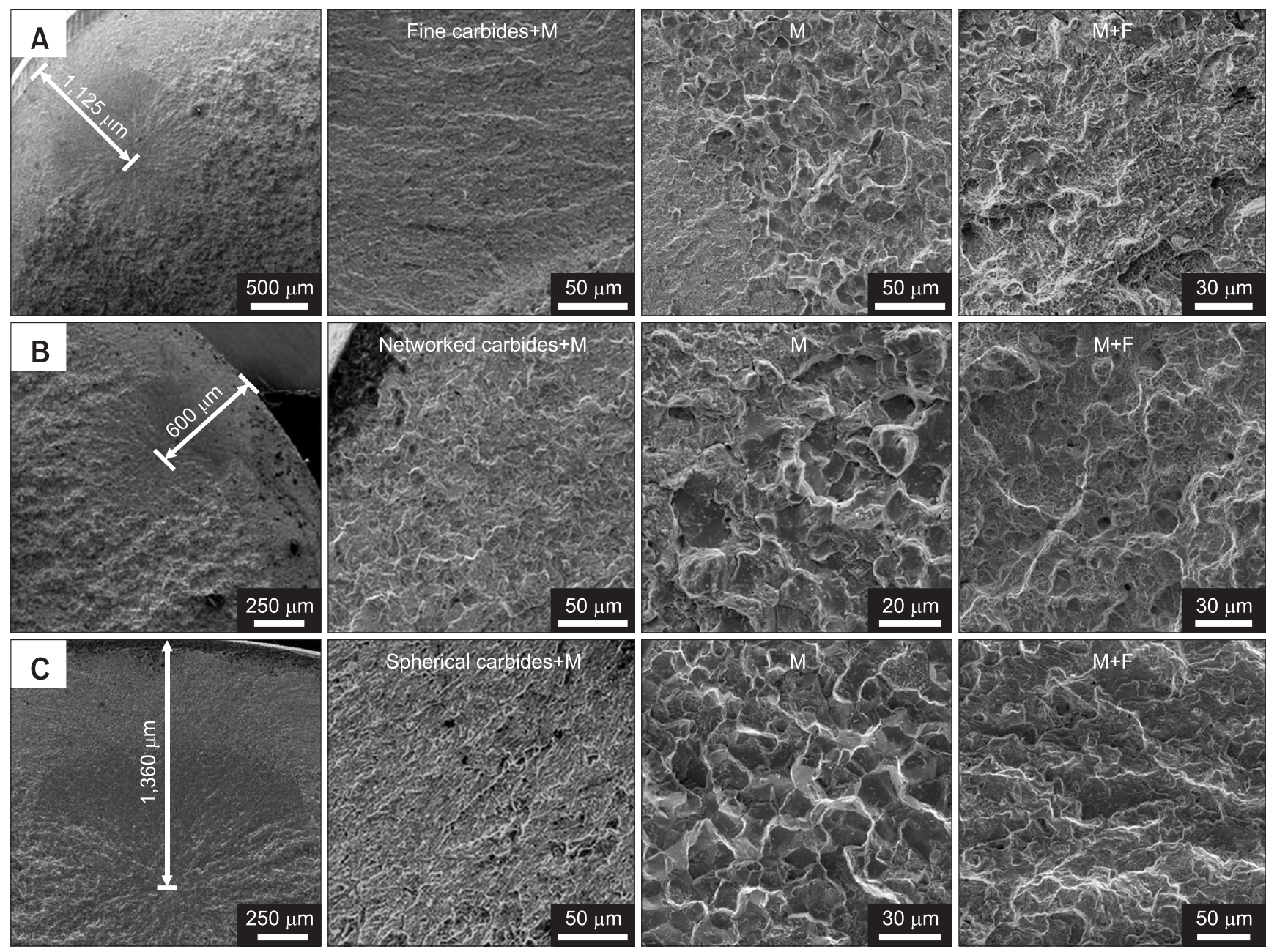

Fig. 9. Fractographies after bending fatigue tests as a function of carbides: fine carbides (A), networked carbides (B) and spherical carbides (C). 
uniformly distributed fine carbides without any abrupt change of the carbide density have a beneficial influence in carburized steels with the improvement of the tensile properties due to the suppression of crack propagation.

\section{Bending Fatigue Property}

Bending fatigue limits of samples with three different carbide types are shown in Fig. 8. As shown in the figure, the samples with fine, networked and spherical carbides had limits of 600 , 525 and $600 \mathrm{MPa}$, respectively. Fractographies after the fatigue test of a sample with spherical carbides are shown in Fig. 9. As shown in the figures, the cracks initiated at 1.125, 0.6 and 1.32 $\mathrm{mm}$ beneath the surface of the fine, networked and spherical carbide conditions, respectively. The intergranular fracture was observed in the martensite regions. This result showed that the cracks initiated in the ferrite and martensite regions, with the exception of the \#2 sample. Thus the cracks in the samples with uniformly distributed spherical carbides in the carburized layer could be formed at the interface between martensite and ferrite phases by repeated force. However, in \#2 sample, the crack was initiated in the martensite and carbide regions. An enlarged micrograph in the Fig. 9B showed that cracks were formed along the grain boundaries. This indicates that the bending fracture should result from networked carbides. As a result, uniformly distributed carbides in the carburized layer should improve the bending fatigue property due to suppress the formation and propagation of the cracks. However, networked carbides along grain boundaries should deteriorate the bending property because they act as formation sites of cracks.

\section{CONCLUSIONS}

The relationship between carbide morphologies and mechanical properties were investigated in carburized steels. In this experiment, three different type carbides, i.e. fine, networked and spherical types, in carburized layers were formed by the control of diffusion and precipitation processes. These carbides were analyzed to have a $\mathrm{Fe}_{3} \mathrm{C}$ structure. The microstructural analyses showed that the mechanical properties were strongly dependent on the carbide types. The uniformly distributed spherical carbides improved the tensile and bending properties due to the suppression of crack propagation and initiation, respectively. However, the networked carbides deteriorated the tensile and bending properties because they act as the path way and initiation of the cracks. Therefore, the morphological control of carbide in a carburized layer should be a critical factor in improving the mechanical properties.

\section{ACKNOWLEDGMENTS}

This work was supported by the Human Resources Development of the Korea Institute of Energy Technology Evaluation and Planning (KETEP) grant funded by the Korea government Ministry of Knowledge Economy, 20104010100620, Republic of Korea and was supported by Hyundai Kia Motors, Republic of Korea.

\section{REFERENCES}

Akita M and Tokaji K (2006) Effect of carburizing on notch fatigue behaviour in AISI 316 austenitic stainless steel. Surf. Coat. Technol. 200, 6073-6078.

An X, Cawley J, Rainforth W M, and Chen L (2003) A study of internal oxidation in carburized steels by glow discharge optical emission spectroscopy and scanning electron microscopy. Spectrochim. Acta Part B At Spectrosc. 85, 689-698.

Chen F S and Wang K L (2000) Super-carburization of low alloy steel and low carbon steel by fluidized-bed furnaces. Surf. Coat. Technol. 132, 36-44.

Elkholy A (1983) Case depth requirements in carburized gears. Wear 88 233-244.

Erdogan M and Tekeli S (2003) The effect of martensite volume fraction and particle size on the tensile properties of a surface-carburized AISI 8620 steel with a dual-phase core microstructure. Mater. Charac. 49, 445-454.
Farfána S, Rubio-Gonzálezb C, Cervantes-Hernándezb T, and Mesmacque G (2004) High cycle fatigue, low cycle fatigue and failure modes of a carburized steel. Int. J. Fatigue 26, 673-678.

Liu L D and Chen F S (2004) Super-carburization of low alloy steel in a vacuum furnace. Surf. Coat. Technol. 183, 233-238.

Michal G M, Ernst F, Kahn H, Cao Y, Oba F, Agarwal N, and Heuer A H (2006) Carbon supersaturation due to paraequilibrium carburization: stainless steels with greatly improved mechanical properties. Acta Mater. 54, 1597-1606.

Parrish G (1999) Carburizing: Microstructures and Properties (ASM International, Materials Park, $\mathrm{OH}$ ).

Tokaji K, Kohyama K, and Akita M (2004) Fatigue behaviour and fracture mechanism of a 316 stainless steel hardened by carburizing. Int. J. Fatigue 26, 543-551. 